\title{
La experiencia de la Asociación Pro- Derechos Humanos de Andalucía en centros de secundaria y bachillerato. El valor de la participación de las entidades sociales en los centros educativos
}

\author{
The experience of the Pro-Human Rights Association \\ of Andalusia in secondary and high school. The value \\ of the participation of social entities in educational centers
}

\author{
Cristina Serván Melero*
}

Recibido: 26 de octubre de 2020 Aceptado: 10 de diciembre de 2020 Publicado: 27 de julio de 2021

To cite this article: Serván, C. (2021). La experiencia de la Asociación Pro-Derechos Humanos de Andalucía en centros de secundaria y bachillerato. El valor de la participación de las entidades sociales en los centros educativos. Márgenes, Revista de Educación de la Universidad de Málaga, 2 (2), 72-82

DOI: https://doi.org/10.24310/mgnmar.v2i2.10577

\section{RESUMEN}

El presente artículo analiza el potencial de la educación en derechos humanos para la mejora del bienestar de las sociedades y la reducción de la injusticia social. Se destaca el papel que las entidades sociales pueden desarrollar en los centros educativos a través de acciones formativas que promuevan la adquisición de conocimientos basados en la experiencia propia de las organizaciones. La reflexión se articula en relación a la experiencia en materia de sensibilización de la Asociación Pro-Derechos Humanos de Andalucía (APDHA) en centros de educación secundaria en la Bahía de Cádiz y la Janda. Para ello se describe el trabajo desarrollado durante los últimos seis años con alumnado de secundaria; desde 2014 han participado en sus programas, más de 15000 alumnos y alumnas de 50 centros educativos de secundaria de la provincia gaditana. La experiencia acumulada a lo largo de los años pone de relieve la importancia de establecer una colaboración positiva entre las entidades del tercer sector y los espacios educativos, contribuyendo así al fortalecimiento de las redes comunitarias. Finalmente se reflexiona sobre el potencial de las entidades sociales para promover cambios en el ámbito educativo que redunden en un mayor compromiso social del alumnado y de los propios centros con la Cultura de Paz y la participación democrática.

Palabras clave: Derechos Humanos; cultura de paz; educación

\section{ABSTRACT}

This article analyzes the potential of Human Rights education to improve the well-being of society and reduce social injustice. The social entities can develop an important role in educational centers through educational 
actions based on their own experiences. This reflection is linked to the experience of the Pro-Human Rights Association of Andalusia (APDHA) in secondary schools in the Bay of Cádiz and La Janda, developing sensibilization actions. It is described the work carried out during the last six years; Since 2014, more than 15,000 students from 50 secondary schools in the province of Cadiz have participated in its programs. The accumulated expertise over the years highlights the importance of the collaboration between third sector entities and educational spaces, thus contributing to the strengthening of community networks. Finally, it reflects about the paper of social entities to promoting a greater social commitment among the students and in the case of the schools with the Culture of Peace and democratic participation.

Keywords: human rights; culture of peace; education

\section{LOS DERECHOS HUMANOS FRENTE AL NEOLIBERALISMO}

Educar para el aprendizaje de los derechos humanos implica asumir conceptos relativos a justicia social, solidaridad, diversidad de culturas, identidades y capacidades, universalidad de derechos y la relación que estas cuestiones mantienen con las desigualdades que se manifiestan en un mundo globalizado.

La Cultura de Paz implica la integración de los derechos humanos como elemento constituyente (Tuvilla, 1998) siendo imprescindible vincular su estudio y aprendizaje al desarrollo de los valores necesarios para la construcción de sociedades democráticas e igualitarias.

Para comprender mejor las circunstancias que establecen la conexión entre paz y derechos humanos, hemos de diferenciar entre paz negativa y paz positiva, tal y como establece Galtung (1998). La ausencia de conflicto violento, en referencia a la paz negativa, no revela violencias estructurales más sutiles y cotidianas descritas de forma más precisa a través de la concepción de paz positiva. Esta perspectiva de la paz, siendo más compleja en cuanto a las condiciones necesarias para su reconocimiento, sitúa a los derechos humanos en una posición valiosa como instrumento para su consecución y mantenimiento.

La presencia de elementos y situaciones de violencia que afectan al desarrollo en condiciones de dignidad de la vida de las personas es un factor clave para analizar la situación de la población en el mundo actual. Según datos del último informe del Global Peace Index, elaborado por el Institute for Economics and Peace (2020), en su evaluación a través de 23 indicadores específicos del estatus en el carácter pacífico de los Estados, la puntuación promedio de todos los países cayó un 0,34\% durante el último año, siendo la novena vez que se manifiesta esta tendencia en los últimos doce años. A esta situación hay que añadir el efecto que la crisis sanitaria por la COVID-19 generará en el ascenso de la conflictividad y la violencia, debido a la contracción económica que la pandemia está provocando en la mayoría de los países. El informe advierte que los países con mayor disposición para la promoción de sociedades pacíficas se encuentran mejor preparados para absorber y superar las dificultades de una crisis humanitaria y económica como no se había visto desde mediados del siglo XX.

En el caso español, la posición en el ranking GPI corresponde al puesto 38 de la tabla, manteniendo la tendencia descendente de los últimos años. Es importante señalar que, a pesar de que los indicadores reflejan claramente que es necesaria una apuesta firme por la implementación 
de políticas que favorezcan la conformación de una sociedad más pacífica, segura y plural, el discurso neoliberal y de ultraderecha es cada vez más notable en todas las capas de la sociedad, siendo un grave obstáculo para abordar estas cuestiones debidamente.

Esta deriva afecta a los propios centros educativos, estos son espacios que reflejan claramente la situación en la que se encuentra la sociedad. En las escuelas se produce una manifestación cada vez mayor de los discursos reaccionarios, presentes en los medios de comunicación y la sociedad en general, encontrando fácil acomodo además en los espacios educativos. Esto hace aún más evidente la necesidad de implementar cambios estructurales en el modelo de escuela pública, tal y como apunta López (2001), destacando la importancia de incorporar elementos de ruptura con el modelo hegemónico neoliberal que ha posibilitado la instauración en la educación pública de actitudes individualistas y competitivas, en clara contradicción con el servicio público que debe prestar esta institución, y que influye notoriamente en la promoción de sociedades más desiguales y excluyentes. La mentalidad neoliberal y la ideología hegemónica se han implantado eficazmente en la escuela para reproducir las políticas dominantes en el momento actual, conformando las personalidades y subjetividades del alumnado de forma que se ajusten a los intereses del modelo de pensamiento hegemónico (Torres, 2017).

En una sociedad globalizada el acrecentamiento de la desigualdad está condicionado por la discriminación a la que se somete a personas procedentes de otras culturas o que representan otras identidades no hegemónicas. Sen (2007) establece que es necesario combatir el pensamiento globalizador identitario, puesto que esta perspectiva es vulnerable a la manipulación, oculta la diversidad de filiaciones y grupos de pertenencia de las personas y promueve la violencia a través de la exclusión identitaria. La mejor forma de plantear una sociedad justa reside, precisamente, en la pluralidad de identidades y el reconocimiento de iguales derechos para todas. Es clave incorporar al modelo educativo la dimensión intercultural como elemento central para la construcción de ciudadanía democrática. Jiménez y Goenechea (2014) desarrollan ampliamente esta cuestión, señalando cómo la incorporación de un modelo de educación para la ciudadanía intercultural es imprescindible para el desarrollo de las competencias necesarias para lograr una sociedad más justa e igualitaria.

\section{EL POTENCIAL EDUCATIVO DE LAS ORGANIZACIONES SOCIALES}

Trasladar experiencias procedentes de la labor de entidades sociales a los centros educativos puede generar referencias alternativas a los principios que el modelo neoliberal plantea en este ámbito (Mella, Rodríguez y Sotelino, 2019). Estas experiencias del ámbito asociativo también poseen relevancia como instrumentos para la sensibilización de la población más amplia, contribuyendo a reducir el silencio que rodea de forma generalizada a las situaciones de injusticia más apremiantes de nuestra sociedad, tratando de combatirlas a través de actuaciones basadas en la construcción de solidaridad y que reivindiquen justicia social.

Las entidades sociales son portadoras de experiencias relevantes que muestran la posibilidad de construir sociedades inclusivas como un crisol de aportaciones diversas y complejas en las que todas las personas aporten y nadie sea rechazado (Hernández, 2003). Nussbaum (2006) 
expone la importancia de establecer un modelo de sociedad verdaderamente inclusivo, que vaya más allá del modelo clásico de contrato social e integre la diversidad de los seres humanos en los principios que rigen la justicia social.

Lograr una sociedad democrática requiere de la existencia de organizaciones con una postura crítica en relación con la labor de las instituciones, demandando la mejora de los mecanismos que aseguran y garantizan el acceso a los derechos humanos. El escrutinio ciudadano constituye un factor clave para evaluar la propia función de servicio a la ciudadanía de la institución gubernamental. Las entidades sociales se sitúan en una posición idónea para poder desarrollarse a modo de escuelas de democracia y fomentar la adquisición de habilidades para la ciudadanía (Alguacil, 2010), fortaleciendo las aptitudes necesarias para la construcción de una sociedad justa y democrática, proporcionando al alumnado recursos para desenvolverse en la esfera de la participación política.

Para trasladar la experiencia de las entidades sociales al ámbito educativo, pueden adoptarse distintos modelos y estrategias. Destacan, por su potencial para generar acción social a través de los centros educativos, las iniciativas basadas en el modelo de Aprendizaje-Servicio (Tapia, 2010). Estos programas se basan en la integración de un contenido curricular teórico con una parte práctica que el alumnado desarrolla de la mano de entidades sociales del entorno comunitario. El resultado de estas experiencias, que proponen "aprender haciendo", otorga una alta relevancia a la práctica comunitaria, provocando un incremento de la responsabilidad y el compromiso social del alumnado participante (Saz y Ramo, 2015), además del fortalecimiento de los vínculos entre los centros educativos y las entidades del tercer sector.

Otra estrategia para llevar contenidos y experiencias desde las entidades sociales a los centros educativos consiste en el diseño de propuestas educativas específicas que permitan desarrollar actividades de sensibilización con el alumnado de los centros. Estos formatos pueden integrar muchos de los elementos y objetivos que caracterizan a las experiencias de Aprendizaje-Servicio, sin requerir una implicación profunda por parte de los centros, generando igualmente un aporte significativo en la adquisición de conocimientos sobre derechos humanos.

\section{LA EXPERIENCIA DE LA ASOCIACIÓN PRO-DERECHOS HUMANOS DE ANDALUCÍA EN EL ÁMBITO EDUCATIVO}

La Asociación Pro-Derechos Humanos de Andalucía (APDHA) es una asociación de ámbito autonómico, sin ánimo de lucro, pluralista, laica e independiente, constituida en el año 1990. Sus principios se corresponden a lo dispuesto en la Declaración Universal de los Derechos Humanos promulgada en la ONU en 1948. Desarrolla una actividad no asistencialista y altamente reivindicativa, siendo referente en materia de activismo y denuncia social. Sus actividades se centran en reivindicar los derechos humanos como instrumentos de transformación social, mediante la denuncia de sus incumplimientos, la sensibilización de la población, el apoyo a los colectivos más vulnerables y la elaboración de alternativas y propuestas de trabajo.

La entidad cuenta con siete delegaciones y una sede andaluza. Organiza su labor a través de seis áreas de trabajo temáticas correspondientes a cárceles, migraciones, marginación, so- 
lidaridad internacional, feminismos y educación. Las personas que integran la entidad están comprometidas con los principios de la asociación, siendo mayoritariamente voluntarias y militantes. También disponen de personal profesional contratado para el desarrollo y seguimiento de proyectos específicos relacionados con la investigación de los flujos migratorios en la frontera sur, la asesoría jurídica de personas migrantes, cooperación con la zona norte de Marruecos y proyectos de sensibilización y educación en centros educativos. En la Bahía de Cádiz, cuenta actualmente con alrededor de trescientas personas en calidad de socias, aproximadamente cincuenta voluntarias y cinco contratadas.

El área de educación centra su labor en la defensa de la escuela pública, gratuita, laica, de calidad y respetuosa con la diversidad. La APDHA defiende que el derecho a la educación es clave para la consecución de todos los demás derechos, y participa activamente en la defensa frente a las vulneraciones que se producen en el ámbito educativo. Además, a través del área de educación, se desarrollan materiales y recursos pedagógicos para la educación y sensibilización sobre derechos humanos, prevención de la violencia de género, interculturalidad y cultura de paz.

Las propuestas educativas pretenden reflejar el valor de la propia identidad de la asociación, compuesta por personas de perfiles diversos, ya sea desde el punto de vista cultural, confesional, generacional, de identidad sexual o de género, nacionalidad, étnico, económico, o de capacidades y habilidades. Experimentar a través del propio colectivo el beneficio de la interculturalidad, el pluralismo y la diversidad es clave imprescindible para la promoción de ciudadanía democrática y la propia evolución identitaria, tal como proponen Bartolomé y Cabrera (2003) a través de sus planteamientos sobre la construcción de ciudadanía y pertenencia a la comunidad.

\subsection{Estrategias para trasladar el activismo al espacio del aula}

La APDHA desarrolla materiales y estrategias para la educación y sensibilización en derechos humanos, orientada principalmente a alumnado de secundaria y bachillerato.

Desde 1998 la entidad ha desarrollado diversos programas dirigidos a centros educativos: talleres basados en juegos y dinámicas para comprender los mecanismos de la discriminación y el racismo, utilización de role play para el aprendizaje de conceptos basados en el articulado de la Declaración Universal de los Derechos Humanos, materiales educativos sobre personas refugiadas para alumnado de infantil y primaria, unidades didácticas sobre la pena de muerte, el derecho de asilo o contra la proliferación de bulos y fake news contra las personas migrantes, etc. También se han implementado actividades de encuentro directo de alumnado con población migrante, como "La Biblioteca Humana", una actividad protagonizada por personas migrantes que se reúnen con alumnado al que relatan sus historias de vida, propiciando el acceso a informaciones que desmontan mitos y estereotipos, entre otras actividades más o menos puntuales que se encuentran siempre en continua ampliación y renovación.

Los programas y actividades de sensibilización de la APDHA se ofrecen a los centros de secundaria y bachillerato y se publicitan a través de la web de la entidad. Se pretende que la colaboración de la APDHA con los centros educativos posibilite el desarrollo de actividades útiles y adaptables a las características de cada centro, tratando de hacer habitual la presencia de la entidad en las aulas. 
La conexión entre la APDHA y el sector educativo ha sido constante desde sus inicios, sin embargo es importante destacar como ésta se vio impulsada y amplificada en la provincia de Cádiz a partir del año 2014. En ese momento el grupo de sensibilización de la APDHA en Cádiz comenzó a desarrollar un programa metodológico para la impartición de talleres, centrado en la participación y reflexión crítica del alumnado, presentando la labor de la entidad como experiencia relevante en materia de derechos humanos. La propuesta pedagógica consiste en la presentación de materiales audiovisuales que muestran, a través de fotografías o videos breves, situaciones de actualidad, cercanía e interés mediático, planteando la oportunidad de desarrollar un análisis crítico desde la perspectiva de los derechos humanos. En dicho análisis se incorporan las acciones concretas que se desarrollan desde la APDHA en la defensa de los derechos que se estén discutiendo en la sesión, mostrando posicionamientos constructivos que desde la sociedad se pueden adoptar frente a las situaciones de injusticia.

Se trata de que el alumnado reconozca las situaciones que aparecen en las imágenes, bien por estar vinculadas con la proximidad geográfica o por ser relevantes a nivel mediático. Un ejemplo de estas imágenes son las llegadas de pateras a la costa gaditana. En muchos casos, estas imágenes corresponden a las playas del municipio o zonas cercanas que el alumnado conoce, o bien han trascendido a través de medios de comunicación y redes sociales. En otras ocasiones son temas de candente actualidad en la prensa internacional expuestos a través de imágenes de atentados terroristas, crisis de personas refugiadas y/o conflictos armados. También se utilizan noticias de prensa local que relatan episodios de discriminación racial, aporofobia, homofobia, desahucios, situación de personas presas, etc. Esta información es planteada como parte de los problemas que existen en la sociedad actual.

Estas imágenes (fotografías o vídeos breves) suscitan el interés del alumnado, al que se le propone que relacione las situaciones presentadas con lo dispuesto en la Declaración Universal de los Derechos Humanos. Se pretende exponer a través de las interpretaciones del grupo de alumnado las contradicciones y controversias entre las diferentes opiniones de las personas participantes. Este diálogo trata de que todos y todas puedan participar libremente con sus puntos de vista, instando a que argumenten sus opiniones. Las personas que facilitan el taller pertenecen a la APDHA y comparten las experiencias que la entidad ha desarrollado en relación con cada tema. La pertenencia a la asociación permite relatar en primera persona como son las respuestas que desde la sociedad civil se pueden dar a las situaciones de injusticia y vulneración de derechos.

Esta forma de seleccionar y presentar los contenidos promueve una alta participación entre el alumnado, ya que la mayoría reconoce las noticas, los lugares presentados o bien han escuchado hablar sobre los temas y casos planteados. También permite la participación de personas de la asociación que ejemplifican el compromiso de la sociedad con los derechos humanos, respondiendo además a la curiosidad del alumnado por la labor de las personas que realizan este papel en la sociedad. La propuesta logra trascender la mera transmisión de contenidos o exposición de casos, generando la oportunidad de reflexionar colectivamente sobre lo que cada persona puede hacer en consecuencia a la problemática planteada.

Las opiniones y argumentaciones del alumnado durante los talleres muestran diversos grados de conocimiento, sensibilidad, correlación con experiencias personales variadas y posicionamientos ideológicos concretos. Las conclusiones de los diálogos son abiertas puesto que en 
cada grupo existen particularidades que influyen en el propio desarrollo del taller; no siempre llega el consenso al grupo y en ocasiones afloran discursos contrarios a los derechos humanos. No obstante, se considera muy valiosa la posibilidad de que emerjan reflexiones propias y diálogo respetuoso en el grupo de iguales. En todos los casos se observa la valorización de los derechos humanos como elemento necesario para combatir la injusticia y la desigualdad.

\subsection{Evolución del programa y modificaciones para mejorar el impacto}

Este formato de talleres, iniciado en el curso 2014/2015, se realizó con aproximadamente 425 alumnos y alumnas de $3^{\circ}$ y $4^{\circ}$ de ESO y $1^{\circ}$ de Bachillerato de doce centros educativos de secundaria de la bahía de Cádiz, impartiéndose diecisiete talleres en total.

En este primer año de implantación, la propuesta se ofreció, a modo de experiencia piloto, a centros concretos que mantenían vínculos estrechos con la labor educativa de la APDHA. Fueron facilitados por personal profesional y voluntario de la asociación, que posteriormente valoró el resultado de la experiencia a través de reuniones organizadas por el grupo de sensibilización de la APDHA. Las impresiones de las personas facilitadoras fueron positivas, señalando el potencial de los materiales para su utilización por personas militantes de la asociación que, sin la necesidad de disponer de cualificación docente, podían aportar su propia experiencia como activista de la APDHA a los debates. En las conversaciones con el profesorado de los centros educativos, se valoró positivamente la participación generada en el alumnado y la idoneidad de los temas expuestos en la presentación. Se valoró también el efecto de la actividad en el alumnado en base a la recepción de expresiones positivas tales como "se nos ha pasado la hora volando", "me ha encantado”, o por la alta participación y atención a los temas. Estas valoraciones generaron el acuerdo necesario para que durante el siguiente curso se implementara la metodología de talleres participativos en la oferta completa dirigida a todos los centros educativos.

Durante el curso 2015/2016 se realizaron 142 talleres en más de 40 institutos de educación secundaria de la bahía de Cádiz, en los que participaron aproximadamente 3500 alumnos y alumnas.

Dada la alta demanda recibida y la buena disposición de los centros educativos en relación con la oferta de talleres, se les plantea a algunos centros concretos la posibilidad de realizar un programa de talleres con mayor continuidad y contenidos a distribuir durante el año escolar. Esta propuesta consistió en un itinerario específico bajo el título "Escuela y Compromiso Social”. Se pretendía así aumentar la presencia de la entidad en los centros educativos durante todo el curso, abordando contenidos generales, específicos y una última parte dirigida a la promoción del activismo entre el alumnado.

Las valoraciones obtenidas en el programa "Escuela y Compromiso Social” fueron positivas, al igual que las correspondientes a la metodología de los talleres. El profesorado, así como el alumnado de los grupos participantes, manifestaron su satisfacción con el programa. No obstante, y a pesar de las valoraciones positivas, se detectaron dificultades relacionadas principalmente con la ejecución de la última fase del programa durante el tercer trimestre. Conforme se aproximaba el final del curso, la escasa disponibilidad de horas de tutoría con el grupo o dentro de las asignaturas de ciudadanía, provocó que la última sesión sobre activismo se ejecutara en menos de la mitad de los grupos participantes. 
En el curso 2016/2017 se impartieron 148 talleres, participando alrededor de 3700 alumnos y alumnas de 50 centros de secundaria de la provincia de Cádiz. La oferta propuesta se flexibilizó de forma que los tutores y tutoras podían elegir el tipo y cronología de contenidos a desarrollar con sus grupos respectivos. Así, el programa "Escuela y Compromiso Social" se mantuvo como propuesta principal de referencia con respecto a cómo trabajar con el alumnado, pero en la práctica, se desarrolló de forma limitada, principalmente según contenidos de interés y concentrando la ejecución de talleres durante el primer y el segundo trimestre principalmente.

Esta flexibilidad y adaptación, así como la consolidación de la dinámica de talleres participativos, generaron un considerable aumento de la demanda. Así, durante el curso 2017/2018, se impartieron un total de 234 talleres, alcanzando casi los 6000 alumnos y alumnas de 50 centros de secundaria. Los talleres realizados correspondieron, en su mayoría, a la temática específica del derecho de asilo y personas refugiadas en un momento en el que la cuestión se situaba en una posición de gran interés en los medios, en la sociedad y en los propios centros educativos.

Ese mismo curso se realizó una evaluación cualitativa sobre el grado de satisfacción por la sesión recibida con 20 grupos de alumnado de $3^{\circ}$ y $4^{\circ}$ ESO y $1^{\circ}$ de Bachillerato de 8 centros educativos de Chiclana (Cádiz). El alumnado participante recibió un taller sobre derecho de asilo y personas refugiadas. Al finalizar el taller, se les propuso a los participantes que valorasen en qué medida les había gustado el taller. Para recoger sus opiniones se utilizó una encuesta anónima muy sencilla, consistente en señalar en la imagen de una diana, formada por cuatro círculos concéntricos, un punto que indicase su valoración al respecto, más cercano al centro de la diana conforme mayor fuera su satisfacción. Para el análisis de los datos, a cada punto señalado en la diana se le asignó un valor numérico correspondiente al sector en el que se hubiera señalado. Se dio el valor 4 al centro de la diana, descendiendo una unidad en cada sector hasta llegar a 0 en el sector más externo. Una vez analizadas las encuestas de los 20 grupos, se comprobó que el grado de satisfacción fue muy alto, con una valoración media de 3,77.

En el curso siguiente, el 2018/2019, se impartieron 159 talleres en la provincia. De nuevo se produce una alta demanda de talleres ya consolidados y con gran aceptación en los centros educativos.

El curso 2019/2020, y a causa de la crisis sanitaria por coronavirus, los talleres sólo pudieron realizarse hasta el 12 de marzo, siendo un total de 93 los talleres impartidos. El resto de la programación tuvo que ser cancelada. Las medidas de confinamiento y las graves consecuencias que la pandemia ha tenido en la comunidad educativa requieren un análisis exhaustivo. Podemos apreciar que, en un momento en el que la perspectiva de derechos humanos es fundamental para analizar y comprender los acontecimientos de la actualidad, la suspensión temporal del acceso a estos talleres en los centros educativos es una mala noticia. Aun así, se mantiene la esperanza de que estas actividades puedan ser retomadas a la mayor brevedad posible y continuar llevando propuestas participativas a las aulas.

\section{CONCLUSIONES Y MIRADA AL FUTURO}

Es imprescindible reivindicar la relevancia de la educación como motor de transformación de la sociedad y la construcción de una cultura de paz. Que las organizaciones sociales y asociaciones 
aporten contenidos, propuestas, alternativas y formas de cooperación con las escuelas es un gesto de responsabilidad para con la sociedad en general. Encontrar formas de vivir colectivamente con dignidad y respeto hacia todas las personas requiere de una implicación de todos los actores que componen la comunidad, también en el ámbito educativo.

Rendón (2018) desarrolla con precisión la tesis de que "todo hecho educativo es un hecho político" y señala el poder de la educación para transmitir un modelo de sujeto y sociedad que actualmente está articulado en beneficio del neoliberalismo. Para las entidades del tercer sector, la escuela supone un espacio imprescindible en el que participar precisamente para aportar un posicionamiento alternativo a la desigualdad y la exclusión que promueve el sistema neoliberal.

Las entidades sociales pueden quebrar el modelo hegemónico, puesto que sus prácticas y experiencias están basadas en intereses, objetivos y cosmovisiones diferentes a las que el neoliberalismo ha introducido en el modelo educativo actual. Esta cualidad se presenta especialmente valiosa para los propios centros, que encuentran en la oferta de las entidades recursos externos con los que abordar unas carencias cada vez más acusadas en materia de participación democrática. Torres (2010) propone la integración de una pedagogía crítica que presente conocimientos en pro de un mundo más justo, integrando la pluralidad de discursos en el debate público y desnaturalizando el fracaso dentro de las instituciones escolares, que ignora las condiciones que limitan las oportunidades de determinado alumnado. En este sentido, la apuesta por una escuela pública y de calidad, protegida frente a las políticas de privatización que las hacen competir con los centros privados y concertados mientras afrontan una merma de recursos humanos y materiales, requiere de una defensa colectiva fuerte que se sustente en la propia comunidad de la que depende y a la que sirve.

Pese a todo, las escuelas son comunidades en las que se puede provocar la aparición de oportunidades dirigidas al bienestar colectivo, siempre y cuando se desarrolle un liderazgo que arranque de la propia comunidad y se base en ideales democráticos (Vázquez, 2018).

El alumnado es altamente receptivo a propuestas en las que, como la descrita en esta experiencia, ejercite sus cualidades para la participación democrática, mostrándose motivado e interesado en iniciativas en las que adquiera protagonismo y sus opiniones cuenten en el desarrollo de los debates planteados. El contacto con realidades subalternas, desde una visión humana y empática, provoca la identificación del alumnado con las desigualdades y problemáticas presentadas, posicionándose mayoritariamente a favor de las estrategias que promuevan la eliminación de la desigualdad y la discriminación. Que los talleres realizados presenten cuestiones de justicia social, y que sean discutidas por alumnado que se encuentra en la etapa adolescente, supone una oportunidad para aprovechar el potencial para la rebeldía de una fase de madurez en la que se posibilita la adquisición de una visión crítica con respecto a las ideologías presentes en la sociedad, cuestionándolas y posibilitando así otras posiciones alternativas a los modelos de dominación autoritaria.

A través del diálogo y la participación paritarias se estarían sentado unas bases imprescindibles sobre las que implementar mecanismos que garanticen el pleno desarrollo de la vida de las personas en condiciones de dignidad. 
Fraser y Honneth (2006) plantean la importancia de converger en estrategias que aborden la desigualdad inherente al modelo social del capitalismo moderno, a través de formas de compensación económica y cultural de forma transversal. Sin embargo estas políticas solo podrán ser eficaces si se dispone de espacios discursivos que refuercen la paridad democrática en los que evaluar la idoneidad de las políticas de reparación. Esta paridad democrática implica el reconocimiento y valoración de todos los actores sociales que participen en el debate público, la articulación de estrategias pedagógicas que redunden incansablemente en el diálogo, el respeto, la participación igualitaria y la capacidad de argumentar con solidez, siendo de imperante necesidad para poder aspirar a un futuro de garantías democráticas.

Nussbaum (2007) considera al ser humano un ser político por naturaleza, que se desarrolla a través de sus relaciones y que necesita de la justicia para vivir en comunidad. Su teoría de las capacidades sitúa en un plano preferencial la comprensión de la vulnerabilidad de la condición humana y su diversidad. Esta vida en comunidad debe potenciarse, al igual que la comprensión de la interdependencia entre seres humanos que necesitan derechos para poder realizarse en condiciones de dignidad. La escuela, las organizaciones sociales, la institución, las culturas y los colectivos diversos que conforman la comunidad necesitan tender puentes que garanticen la sostenibilidad de la ineludible interdependencia de los seres humanos. Estas relaciones merecen ser visibles en la vida cotidiana de la comunidad para así poder transformarla para el bien común.

Afirma Santos (2017) que el pensamiento ortopédico de occidente posee una carencia epistemológica para captar la inagotable diversidad del mundo. A menudo ese pensamiento ortopédico se traslada a sistemas más pequeños y cercanos, como es la comunidad de la escuela, trascendiendo las distancias epistemológicas norte-sur. Como este autor señala, urge expandir el presente para evitar el desperdicio de experiencias sociales que se están desarrollando al mismo tiempo en el mundo actual, y contraer el futuro trabajando con intensidad y persistencia en las oportunidades que emanan de nuestro tiempo. Este es un año de crisis sanitaria en el que el mantra "que nadie se quede atrás" se ha cargado de significado; aprovechemos la oportunidad para mantenerlo en nuestro horizonte hasta que no haya que invocarlo porque sea una realidad lograda.

\section{REFERENCIAS}

Alguacil,J. (2010). Ética, nueva ciudadanía y democracia. Documentación social. Revista de Estudios Sociales $y$ de Sociología Aplicada 159, 27-44.

Bartolomé, M. y Cabrera, F. (2003). Sociedad multicultural y ciudadanía; hacia una sociedad y ciudadanía interculturales. Revista de Educación, (1), 33-56.

Fraser, N.y Honneth, A. (2006). ¿Redistribución o reconocimiento? Un debate político-filosófico. Morata.

Galtung, J. (1998). Tras la violencia, 3R: reconstrucción, reconciliación, resolución. Afrontando los efectos visibles e invisibles de la guerra y la violencia. Gernika Goforatuz.

Hernández, A. (2003). Ciudadanía y espacio público: participación o segregación. En Alguacil, J. (ed). Ciudadanía, ciudadanosy democracia participativa (pp.15-39). Fundación César Manrique.

Institute for Economics \& Peace. Global Peace Index (2020). Measuring Peace in a Complex World, Sydney, June 2020. http://visionofhumanity.org/reports 
Jimenez, R. y Goenechea, C. (2014). Educación para una Ciudadanía Intercultural. Síntesis

López Melero, M. (2001). "Cortando las amarras de la escuela homogeneizante y segregador. XXI Revista de Educación, 3, 15-53. https://bit.ly/2VJgU9s

Mella, I., Rodriguez, M.A., Sotelino, A. (2019). El papel de las entidades cívico-sociales en el AprendizajeServicio. Sistematizando la participación del alumnado en el tercer sector. Revista Teoría de la educación, 31(2), 197-219. https://doi.org/10.14201/teri.20156

Nussbaum, M. (2007). Las fronteras de la justicia. Paidos.

Redón, S. (2018). La pedagogía crítica como pedagogía en símisma. En Vázquez, R. (Coord.) Reconocimiento $y$ bien común en educación. (pp. 231-258). Morata

Santos, B. de S. (2017). Justicia entre saberes. Epistemologías del Sur contra el epistemicidio. Morata.

Saz, M. I. y Ramo, R. M. (2015). Aproximación a los impactos y beneficios del aprendizaje servicio en la Universidad de Zaragoza. Revista Iberoamericana de Aprendizaje Servicio, 1(9-27). https://doi. 10.1344/ RIDAS2015.1.2

Sen A. (2007). Identidady violencia. La ilusión del destino. Katz.

Tapia, M. N. (2010). La propuesta pedagógica del "aprendizaje-servicio": una perspectiva Latinoamericana. Revista cientifica TzhoeCoen, 5 (23-44). https://bit.ly/33Lloks

Torres, J. (2010). Currículum, justicia e inclusión. En Gimeno J. (Coord.) Saberes e incertidumbres sobre el currículum. (pp. 84-102). Morata.

Torres, J. (2017). Políticas educativas y construcción de personalidades neoliberales y neocolonialistas. Morata.

Tuvilla, J. (1998). Educación en Derechos Humanos: Hacia una perspectiva global. Desclée de Brouwer, S.A.

Vázquez, R. (2018). Las paradojas de la cultura de la gestión y del liderazgo en el (des)encuentro de la ciudadanía y la sociedad neoliberal. En Vázquez, R. (Coord.) Reconocimiento y bien común en educación (pp. 119-155). Morata. 